\title{
Recordatorios importantes y necesarios para el mundo de hoy ${ }^{1}$
}

\author{
Rodolfo Cardenal, \\ Centro de Reflexión Teológica, \\ San Salvador.
}

En estos tiempos, cuando se levantan vientos amenazadores de guerra, es necesario trabajar con denuedo para construir la paz. En los pocos años que han transcurrido del siglo XXI ya ha habido varias "guerras de la pobreza" -Afganistán y Congo-, a las cuales se ha venido a agregar ahora "la guerra preventiva" contra Irak. La paz es, pues, un inmenso reto actual para los hombres y las mujeres de buena voluntad, y un compromiso ineludible para quienes nos confesamos cristianos. En este contexto queremos ofrecer algunos recordatorios importantes que aporten luz y ánimo a la tarea. Nos referimos a la tradicion del Concilio Vaticano II, proseguida en Medellín, la teología de la liberación, Mons. Romero y la tradición martirial salvadoreña, y, más específicamente, al pensamiento de Ignacio Ellacuría. No vamos a decir nada nuevo, pero sí queremos insistir en la importancia de recordar cosas fundamentales, pues somos proclives a olvidar y a mantener el vigor y el rigor con que antes se decían las cosas.

Las reflexiones de Ellacuría sobre la paz y, en concreto, sobre lo que, según él, debiera ser el aporte específico del cristiano ("Violencia y cruz", p. 427ss.; "La paz mundial vista desde el tercer mundo", p. 489ss.; "Teología de la revolución y evangelio", p. 483ss. y "Trabajo no violento por la paz y violencia liberadora", p. 501 ss., Escritos teológicos III, San Salvador, 2002) me parecen muy oportunas. No se trata sólo de exponer su pensamiento teórico, más relacio-

1. Este texto fue leído en el homenaje que Swarthmore College (Filadelfia) rindió al profesor de filosofía Hugh Lacey, el 21-22 de marzo de 2003, con motivo de su jubilación. Quiero aquí expresarle mi agradecimiento. Hugh Lacey tradujo algunos de los textos más relevantes de los mártires de la UCA y los publicó en inglés. En sus clases y conferencias con frecuencia utiliza los escritos de Ignacio Ellacura. 
nado con la actividad académica, sino de comprender su actualidad y, sobre todo, su capacidad para transformar nuestra realidad. Lo más importante ahora no es, pues, conocer y discutir sus escritos, sino leerlos e interpretarlos desde nuestra realidad actual para iluminarla, y explorar sus posibilidades de cambio.

\section{La perspectiva cristiana de la paz en un mundo violento}

La paz es extraña. Es uno de los bienes más deseados y apreciados por la humanidad, pero al mismo tiempo es uno de los bienes más frágiles y sorprendentemente rechazados. El deseo de paz es tan poco eficaz e inconsistente que, con frecuencia, se convierte en violencia. Al igual que las generaciones del siglo pasado, estamos siendo testigos de cómo la paz no es duradera. El siglo pasado está configurado por períodos intermedios entre dos grandes guerras, pero incluso esos intermedios no son tiempos de paz, sino tiempos dedicados a preparar el siguiente conflicto bélico. Por eso, cuando los grandes del mundo hablan de paz entre ellos, se parecen mucho a los falsos profetas de Israel, a quienes Ezequiel llama hombres de "visiones vanas y predicciones mentirosas" $(13,6)$, porque extravían al pueblo cuando hablan de paz, pues en realidad, "no hay paz". Desgraciadamente, se vive, más bien, según la lógica de la antigua Roma imperial, si vis pacen, para bellum, y no según la lógica de Ezequiel.

La globalización, sin duda, ha traído cosas buenas, pero también nos ha sumergido en un mundo violento, con sus secuelas de inseguridad e incertidumbre. Es, pues, necesario hacer un balance cuidadoso de los bienes y males del fenómeno de la globalización, pues desde hace algún tiempo, quizás sin saberlo bien, hemos estado viviendo inmersos en múltiples formas de violencia. Casi podríamos decir que la violencia se ha vuelto algo natural en nuestras vidas. Nos hemos acostumbrado a ella y hasta hemos aprendido a convivir con ella con naturalidad. En esa misma medida, nos hemos vuelto insensibles a ella y nos hemos ido deshumanizando, tal vez sin caer en la cuenta. Es así como tenemos el raro privilegio de ser testigos de cómo las relaciones entre las naciones y entre los bloques de naciones se siguen rigiendo por la fuerza y la violencia, y no por el deseo de construir la paz, hasta el punto de considerar la guerra como la mejor opción para resolver las diferencias. Esta realidad es la mejor crítica a quienes todavía defienden que el triunfo del capitalismo, tras la guerra fría, puso Final a la historia o a quienes tienden a pensar que el derecho, la verdad, la justicia y la paz representarían problemas prácticamente superados.

La lógica de la guerra no debe distraemos y hacer olvidar otra lógica que es también mortal y que es todavía más primigenia. Es la lógica que genera el hambre y la enfermedad e, inevitablemente, la muerte de una gran parte de la humanidad. La pobreza masiva que encontramos a nuestro alrededor es, en sí misma, una violencia contra seres humanos con derecho a la vida y a la digni- 
dad. Por eso, la pobreza, tal como lo denunció Medellín, es un atentado contra la paz. Ellacuría la Ilama violencia institucional y la considera, ademas, el origen de toda oura forma de violencia. Esto significa que sin erradicar este origen primario de toda forma de violencia, es imposible construir una paz sólida y permanente. Este es un primer recordatorio sumamente necesario, aunque se quiera prescindir de él.

Estas palabras pudieran parecer hoy radicales, pero no debieran sorprender y de ahí la necesidad de un segundo recordatorio. Lo que acabamos de decir no es una novedad introducida por teólogos de la liberación, como Ellacuría. Ya Juan XXIII, en la Pacem in terris, cuyos cuarenta años acabamos de celebrar, habla de la paz justa como desarrollo integral y equitativo de personas y pueblos. Desde entonces, la paz ya no se define en términos negativos y en contraposición a la guerra, sino que está asociada, al igual que en la Biblia, a la justicia y al derecho. Hace cuarenta años, el Papa llamó la atención sobre el contraste entre el despilfarro de la producción de armamentos y la situación de miseria de una gran parte de la humanidad. En este contexto, Juan XXIII calificó la cartera de armamentos como crimen contra los pobres.

El Concilio Vaticano II, pese al optimismo que muestra frente al mundo y al progreso humano, no pasó por alto que la mayor parte de la humanidad vive en condiciones inhumanas, las cuales no son atribuibles a su responsabilidad o a su negligencia, sino a la injusticia y a la opresión. El Concilio considera que ésta es una situación escandalosa, infamante y degradante, porque destruye la persona, y, con ella, la imagen del Creador y del Redentor. En consecuencia, condena con energía el exterminio sistemático de pueblos enteros y hace un reconocimiento público del valor de quienes no temen a quienes ordenan esas soluciones. El remedio a estos males debiera ser pronto y eficaz, en contraposición a la excesiva lentitud con la cual se buscan soluciones eficaces. A veces lo que hay es indiferencia e incluso hipocresía.

Dando un paso más, el Concilio atribuye esa situación al pecado, pero no a un pecado impersonal, en el cual la mala conciencia del poderoso busca refugio, sino al deseo de dominio, al desprecio a las personas, a la envidia, a la soberbia, al egoísmo, en suma, a la negación directa del amor. Este pecado tiene tal proporción y es tan mortífero, que nos coloca ante el lado más oscuro de la realidad humana, ante el misterio de la iniquidad. Es una maldad que aumenta la codicia, que se esfuerza por mantener la buena conciencia y que hace olvidar que el Evangelio es incompatible con esa situación de pecado. Recurre a la mentira para esconder su maldad y acostumbra justificar su desprecio a la persona y su olvido del Evangelio con leyes económicas y teorías en apariencia sólidas. Pero no se queda sin respuesta, porque el profetismo desvela su maldad. Y al mismo tiempo que la profecía denuncia públicamente la maldad, anuncia la 
construcción de la paz. La paz avanza cuando hace retroceder las realidades que la amenazan o la niegan.

Podríamos continuar haciendo un recorrido por el magisterio universal y latinoamericano más reciente, pero basta con invocar la autoridad del último concilio ecuménico. Esta postura profética del Concilio Vaticano II recoge el espíritu de los dos testamentos, donde la queja contra la injusticia que genera violencia es constante. Ellacuría insiste en que para quien toma en serio el Antiguo Testamento, calegorías como Egipto, Babilonia, bestia, cautividad y persecución, le deben recordar una serie de situaciones de grave pecado.

El presupuesto que otorga vigor especial a estas categorías es la idea de un pueblo elegido. Es cierto que en los inicios se trata de un pueblo determinado, pero a través de la idea de "resto perseguido", se produce una apertura a la universalidad. Se trata de un resto que necesita ser liberado, porque está oprimido y sufre. A medida que se convierte en pueblo de pobres, gana en universalidad y pierde en connotación racial. En este contexlo, es evidente la importancia de Ia interpretación bíblica de Egipto. Al comienzo fue lugar de asilo y protección, pero luego se convirtio en lugar de opresión y muerte, se transformó en Babilonia, la encarnación manifiesta del abuso. Babilonia es un poder demoníaco, expresado en la categoría de la bestia. Y ante el poder demoníaco de la bestia surgen los reclamos apocalípticos.

Otra categoría bíblica importante en relación a las anteriores es la de endurecimiento. El pecado endurece al opresor, quien se agarra a él con fuerza, lo racionaliza y lo justifica. La luz que el profeta, en nombre del perseguido y del que sufre, hace brillar ante sus ojos, en lugar de iluminarlo, ciega al opresor. "iAy de los que llaman noche al día y día a la noche". Y entonces surge el peor de los pecados, el pecado contra la luz. El endurecimiento despierta la cólera divina y el castigo. "Ay de los que decretan decretos inicuos", clama Isalas, "excluyendo del juicio a los débiles, atropellando el derecho de los pobres de mi pueblo... pues, ¿qué harán para el día de la cuenta y la devastación que de lontananza viene? ¿A quién acudirán para pedir socorro?" (10, 1-4).

Estas categorías, que expresan la negatividad, tienen su correspondencia -recalca Ellacuría- en otras que llevan a la salvación: expiación, penitencia, conversión y reconciliación. La primera respuesta exigida al pecador es la conversión, que responde a la redención subjetiva inicial. La denuncia del mensaje profético exige la conversión profunda y radical del corazón. Es el paso de un corazón, que busca como a su dios el poseer y el poder, a otro dedicado ahora al servicio y al amor. En seguida, la conversión exige expiación y penitencia. No tanto como castigo o pena por el pecado cometido, sino como muerte a un modo de ser, al hombre o a la mujer vieja. Al morir a esa manera de ser, se entra en una nueva vida. Pero a ella sólo es posible llegar por medio de la 
muerte. Es un morir a la vida anterior. Como toda muerte, ésta suele ser dolorosa, pero necesaria para entrar a formar parte de la nueva realidad.

$\mathrm{Al}$ abordar esta temática en el Nuevo Testamento, Ellacuría se centra en la fuerte denuncia de Santiago: “ ¿Acaso no ha escogido Dios a los pobres según el mundo para hacerlos ricos en la fe y herederos del reino que prometio a los que lo aman? En cambio, ¡ustedes han menospreciado al pobre! ¿No son acaso los ricos los que los oprimen y los arrastran a los tribunales? ¿No son ellos los que blasfeman el hermoso Nombre que ha sido invocado sobre ustedes?" (2, 5-7). En lo fundamental, el pensamiento es el mismo. Los ricos que oprimen al pobre y le arrebatan lo que le es debido, están llamados a perecer. En cambio, sobre los pobres se ha invocado el nombre de Dios y la ofensa contra ellos es una ofensa contra Dios. Los gritos de los oprimidos han llegado al cielo. El Señor de los ejércitos se levanta para el castigo y su señal es la herrumbre de la riqueza acumulada. Mientras llega el Señor, Santiago pide paciencia al justo, pero a Dios le pide ser impaciente (1, 5-6). El nombre de Dios ha sido invocado sobre los pobres no porque éstos sean mejores que los ricos, desde una perspectiva moral, sino por el simple hecho de haber sido desposeídos de los bienes de una creación, de la cual nadie debía haber sido excluido.

La opresión es, pues, uno de los pecados que más despierta la cólera divina, porque viene a ser como el odio del Maligno, el cual, al no poder dirigirse contra el Señor, se dirige contra sus hijos e hijas. En definitiva, es la obra del misterio de la iniquidad en la humanidad. Pero los discípulos de Jesucristo y cuantos odian la injusticia debemos esforzamos por cerrar la fuente de tanta maldad y muerte.

\section{La contribución del cristiano a la paz}

El cristiano no puede permanecer pasivo ante el pecado de la injusticia y la violencia -ni ante ningún pecado. En varias ocasiones, Ellacuría insistio en el gran mal que es la violencia en sí misma. "La violencia", solía advertir, "es siempre un mal mayor de lo que se piensa". Cuando hablaba así, tenía en mente a los fanáticos de la violencia y a quienes hacen de ella una mística. En una afimación muy típica suya, escribió que "sólo los pacifistas deberían hacer la guerra". Con esta formulación provocativa, quería subrayar el cuidado con el cual habria que aceptar la violencia, aun aquella que pueda considerarse legítima. $Y$ en ningún caso, puede convertirse la violencia en un valor absoluto, porque entonces se convierte en ídolo que exige el sacrificio de incontables víclimas humanas, incluso el de sus propios adoradores, a quienes también aniquila. El ídolo no es fuente de vida y gozo, sino de muerte y dolor.

Cuando la violencia no puede ser evilada, Ellacuría considera un deber reducirla de una forma radical y utilizar el principio de proporcionalidad en la respuesta. Pero la actitud más radical es prevenir su estallido, eliminando sus raf- 
ces, es decir, la injusticia, y para ello es indispensable enfrentar la concupiscencia del dinero. Pablo, en Colosenses $(3,5)$, afirma que la concupiscencia del dinero es una de las causas de la cólera de Dios. El Evangelio repite con fuerza que es contraria al primer mandamiento, e incluso es una ofensa a Jesucristo, escondido en las apariencias profanas de los débiles y oprimidos. Mateo insiste en esta verdad, en su visión anticipada del juicio final (25). Por eso, el Evangelio primero, y la tradición cristiana después, desconfían de ella. El fruto de la codicia es la injusticia y, en particular, el atropello del débil, y por ello es uno de los pecados más fustigados en la Biblia, y, sin embargo, la codicia es una de las fuerzas que mueve la historia de la humanidad.

Ahora bien, la contribución específica del cristiano a la construcción de la paz no es sólo evitar la violencia, sino redimirla. En la tradición cristiana, la redención implica la cruz, el sufrimiento y la muerte, y esto hay que entenderlo bien. No obstante una tradición católica clásica que sostiene lo contrario, no se puede afirmar que Jesús busca la cruz, porque desea un sacrificio cruento. Jesús no se encarna para ser crucificado. Jesús se encontró con la cruz, en su entrega incondicional al reino de Dios. El Evangelio da testimonio abundante de que su misión era anunciar la buena noticia de ese reino, una oferta de salvación para la humanidad entera. Pero como sus fundamentos son la justicia y el derecho, el reino es contrario a los poderes del mundo, sobre los cuales Jesús advierte a sus discípulos. Ante el gobernador romano, Jesús declara "mi reino no es de este mundo... no es de aquî" (Jn 18,36), donde por mundo hay que entender "el orden" del poder y de la fuerza, es decir, el orden del pecado. El anuncio de Jesús, sin embargo, no fue aceptado por los dirigentes de ese mundo. Su rechazo es lo que hizo que la salvación pasara por el sacrificio cruento de la cruz. Por fidelidad a su misión, Jesús tuvo que aceptarlo.

La vida de Jesús muestra también con claridad que la salvación no acontece desde arriba y desde fuera, sino desde abajo y desde dentro. Jesús se abre a la transcendencia y la exaltación desde la encarnación y la cruz. En consecuencia, el primer deber del salvador es encarnarse entre quienes pretende salvar. En esto consiste el misterio del Siervo de los cantos de Isaías. Nunca hizo mal a nadie. Rechazado y contado entre los malhechores, fue destrozado de tal manera que lo despojaron de su forma humana. Destruido, fue abandonado y despreciado. Sin embargo, desde esta experiencia radical de despojo y abandono brota la salvación, porque desde la inhumanidad extrema aflora la luz de la plenitud que se anuncia ("El pueblo crucificado. Ensayo de soteriología histórica", Revista Latinoamericana de Teología 18, 1989, p. 326). Esa luz, sin embargo, sólo es visible desde la fe. Sólo desde ella es posible ver luz y encontrar salvación en el cuerpo del Siervo traspasado. Su luz penetra en la profundidad del corazón humano y pone al descubierto sus egoísmos y sus miserias, pero también sus ansias de liberación y de amor. Esta es la síntesis que hace Ellacuría de la historia de Jesús y de tantos otros, hombres y mujeres, entre ellos el mismo 
Ellacuría y sus compañeros, quienes también entregaron su vida a la causa del reino de Dios.

Desde Jesús. no hay redención sin algún tipo de cruz. La redención busca salvar de su miseria y de su maldad al mundo, configurado por la concupiscencia del dinero y del poder. La oscuridad y el pecado del mundo imponen la redención. En la medida en que este mundo retrocede, se avanza hacia la luz y la gracia, que siempre es un don. Pero para avanzar hay que romper las ataduras del egoísmo, lo cual conlleva sacrificio y, a veces, la enırega de la propia vida. Creer que existe otra altemativa de salvación es un error, desde el punto de vista de la sociología y ciertamente de una teología cristiana.

Es un error desde la sociología, porque los poderosos, los responsables últimos de la injusticia y la violencia, no pueden convertirse y cambiar sin sacrificar su codicia y su modo de vida, lo cual entraña, sin duda, una violencia radical para sus personas. Por eso, la cruz puede resultarles intolerable. Por otro lado, la resistencia al cambio casi siempre proviene de quienes tienen riqueza y poder; para ellos, aceptar la conversión, significaría renunciar a sus posesiones y a una vida a la cual están tan acostumbrados que no se pueden imaginar viviendo otra diferente. Así, pues, la violencia derivada del pecado sólo puede ser redimida por otra forma de violencia. Es una violencia distinta, por supuesto, ya que está configurada por la utopía del bien. En sentido estricto y desde la fe cristiana, por el reino de Dios. Quizás por eso el Evangelio afirme que sólo los violentos lo arrebatan.

Es también un error teológico, porque el grano de trigo, para dar fruto, debe caer en tierra y morir. No en vano el autor de Hebreos, apunta Ellacuría, sostiene que "según la Ley, casi todas las cosas han de ser purificadas con sangre, y sin efusión de sangre no hay redención" $(9,22)$. Aunque esta sentencia no hay que entenderla de manera literal, la redención exige purificar y renovar, renunciar y crear. Para renovar y crear, primero es necesario purificar y renunciar. La resurrección acontece tras la más dolorosa de las renuncias y de las muertes. Dios levanta de la muerte a la víctima Jesús, y desde entonces, la resurrección es la esperanza de la muerte redentora. Es una esperanza que aguarda a que esta tierra injusta y violenta pase y dé lugar a la nueva tierra, habitada por una humanidad también nueva. En eso consiste la bondad de la noticia que Jesús trae. La buena noticia no ahorra el mal y sus consecuencias, pero promete que la última palabra no es la de las fuerzas oscuras del pecado, sino la de la luz y la gracia. La tierra y la humanidad nuevas constituyen uno de los deseos más genuinos del corazón de los creyentes. Las semillas de esta promesa ya están sembradas, y aunque su plenitud está más allá de la existencia terrena, sus primeros retoños pueden verse ya desde ahora, en la generosidad de los seguidores de Jesús y de los hombres y las mujeres de buena voluntad, que han dedicado su vida a hacerla posible. La paz y el amor, cuyo fundamento es la justicia y 
el derecho, deben reinar en esta tierra. Cuando esto se lleve a cabo, Dios culminará su encarnación en la humanidad. Mientras tanto, esos primeros retoños son una poderosa razón que alimenta la esperanza.

Los cristianos, por lo tanto, debieran ser los primeros y más arriesgados en combatir toda forma de injusticia. aunque sin hacer uso de la violencia. El cristiano no da testimonio de su fe, ni de su esperanza a través de la violencia, sino mostrando cómo el perdón está sobre la venganza, la vida está sobre la muerte, el amor sobre el odio. Su misión consiste en poner acontecimientos que detengan la espiral de violencia, que destruye a la humanidad y que, al mismo tiempo, desaten el nuevo dinamismo de la justicia y la paz, los fundamentos del reinado de Dios. Cuando un cristiano toma en serio su misión, se dispone también a ser "el primero y el más arriesgado" y, si fuera necesario, llega "hasta el martirio", agrega Ellacuría.

La violencia cobra realidad en sus víctimas. Ante ellas, el cristiano no puede mostrarse indiferente, ni pasar de largo. Las víctimas deben moverlo a la compasión, es decir, a padecer con ellas. La compasión no es una actitud pasiva, sino que mueve a colocarse al lado de las víctimas, a sufrir con ellas el despojo y la humillación, y a tratar de aliviar su dolor. Pero esto no es todo, se puede ir más lejos. La compasión debe llevar a intentar evitar que siga habiendo víctimas. Ellacuría lo expresó de una manera audaz al afirmar que el discípulo de Jesús es aquel que intenta bajar de la cruz a las víctimas crucificadas por el egoísmo. Son pueblos enteros los que están crucificados por el hambre, la enfermedad y la guerra. Son las cruces de la historia o del pecado de la humanidad. Ante ellas, el cristiano no puede pasar de largo, la piedad reclama bajar a esos crucificados de sus cruces.

Desde esta perspectiva, Ellacuria interpreta la dimensión salvífica de la cruz de Jesús con una metáfora, siguiendo en esto las huellas de Pablo. Jesús habría dejado que la violencia desahogase contra él toda su fuerza, hasta quedar agotada. Sin fuerzas, la violencia ya no podrfa cobrar nuevas víctimas. Si éste es el camino, el cristiano, en su afán por ser fiel al reino de Dios, enfrenta la posibilidad real de ser triturado por la violencia que pretende redimir. El riesgo aparece porque actúa de manera indefensa, ya que rechaza la violencia. Este riesgo no es un simple costo social que es necesario pagar para alcanzar la paz, sino que es la contribución específicamente cristiana. El cristiano hace suya la violencia para redimirla; se enfrenta a ella para transformar su dinamismo mortífero, en otro de vida y amor. Su actitud radical es la indefensión, aunque no por eso es menos eficaz. Es la actitud del Siervo sufriente de Isaías, quien sucumbe al poder del pecado que quita: "El siervo justificará a muchos porque cargó con los crímenes de ellos". De nuevo, sólo desde la fe es posible encontrar salvación, en el Siervo traspasado. 


\section{La justicia es el fundamento de la paz}

Decía ya Isaías que la paz no es mera ausencia de guerra, sino que es obra de la justicia, opus iustitiae pax. Así se lee en Pacem in terris, y lo acaba de recordar Juan Pablo II en su mensaje para la jornada de la paz de este año, cuarenta años después de la encíclica de Juan XXIU. Esa justicia sobre la cual se construye la paz no es otra cosa que un orden mundial que garantice a la humanidad la satisfacción de sus necesidades básicas, donde la dignidad de las personas sea respetada, donde su derecho a la verdad sea reconocido y donde su libertad personal esté garantizada. Es lo que el episcopado latinoamericano describí hace tiempo como "el paso de unas condiciones menos humanas a unas condiciones más humanas de vida" (Medellín, Paz, 20ss.).

No queda, pues, otra altemativa que trabajar para poner en marcha una sociedad mundial y local más afín con ese ideal de la fe cristiana. En este contexto, hay que valorar el aporte de Ellacuría y su radical novedad. En contraposición a la predominante civilización de la riqueza habló de construir una civilización de la pobreza. Su idea no es, obviamente, promover un empobrecimiento general como ideal de vida, sino subrayar que lo que unos pocos acumulan falta a la inmensa mayor pare de la humanidad. Eso ni ha resuelto el problema de la vida de los pobres, ni ha civilizado a los humanos. También Juan Pablo II exige un cambio radical y habla de crear una civilización del amor, pero de un amor eficaz, que se traduce en acciones, eficacia que se pone a prueba en la apertura para compartir. $\mathrm{Y}$ los informes anuales de Naciones Unidas sobre el estado de la humanidad sostienen que es posible caminar en esa dirección: con un mejor reparto de la riqueza mundial, los millones que en la actualidad sobreviven en la miseria podrían tener sus necesidades básicas satisfechas. Si el amor fuera eficaz, tal como pide Juan Pablo II, habría mayor equidad en el mundo.

El cambio radical es, pues, posible y necesario, y si la propuesta de Ellacuría de una civilización de la pobreza despierta temor, podríamos hablar de una civilización de mayor austeridad, en la vida personal y colectiva, para hacer posible la vida de la mayor parte de la humanidad, a quien este derecho le es negado, en la actualidad. Cualquiera que sea el término que escojamos. la idea fundamental es clara.

Y recordemos lo fundamental: en esto está en juego la paz. Entendida como justicia, la paz sólo será realidad cuando la acumulación no sea el motor de la historia y cuando la posesión y el disfrute de la riqueza no sea el principio de humanización. Frente a estos criterios predominantes en la actualidad, Ellacurra propone también, siguiendo las enseñanzas de Juan Pablo II, la dignificación del trabajo. Un trabajo que tenga como objetivo principal el perfeccionamiento y la plenitud del trabajador y, por lo tanto, que sea un medio, personal y social, para asegurar la satisfacción de las necesidades básicas. Si el trabajo sostiene la vida y abre posibilidades para satisfacer las aspiraciones legítimas de las personas, 
las desigualdades hirientes desaparecerían. La aspiración última es construir una sociedad donde la riqueza no sea el valor supremo y donde no fuera necesario ser rico para alcanzar la realización y la plenitud humanas.

Este planteamiento contradice las ideas más comunes sobre la persona y la sociedad, y sobre los medios para alcanzar su desarrollo. Propone, por consiguiente, un cambio de perspectiva. La realidad humana no debe ser mirada desde la riqueza, sino desde la mayoría de la humanidad empobrecida y abocada a la muerte por hambre, enfermedad y guerra. Es lo que Ellacuria, y los teólogos de la liberación, han llamado la opción preferencial por los pobres. De hecho, quienes tienen poder para decidir, hasta ahora han decidido más desde los ricos y poderosos que desde la mayoría de la humanidad. Y las consecuencias son evidentes. Esas decisiones han producido más males que bienes a la humanidad. Es cierto que para algunas naciones o bloques de naciones han producido bienes, pero esto no puede afirmarse desde una perspectiva global. Aun cuando hayan traído algunos bienes indiscutibles, en su totalidad, no es una opción cristiana.

Una sociedad como la sugerida daría paso a otra fundada en la austeridad, más coherente con el Evangelio de Jesucristo, que pide compartir los bienes y la vida. En esta sociedad, virtudes como la abnegación, la donación de sí mismo, la esperanza en Dios, la humildad y el amor tendrían el terreno preparado para desarrollarse de forma plena. La virtud fundamental que puede hacer posible este proyecto es la de la solidaridad compartida, en contraposición al individualismo cerrado y competitivo. La solidaridad compartida quiere ver a los otros no como una parte de uno mismo, sino verse a sí mismo en unidad y comunión con los otros y las otras. Esta es una virtud esencialmente cristiana. Su clave radica en la disposición, también cristiana, a dar la vida por los demás, de modo que, en esa entrega, cada uno se encuentre a sí mismo.

La apertura para darse a sí mismo a los demás abre también al espíritu. El ideal cristiano es encontrar la felicidad en el dar y no en el recibir, en la solidaridad y no en el enfrentamiento, en la comunidad más que en el individualismo, en el desarrollo personal más que en la acumulación de cosas. Quienes vivan de acuerdo a estos principios cristianos serán hombres y mujeres con espíritu, porque no estarán movidos por el odio, sino por la misericordia y el amor. En todos ven hijos e hijas de Dios y no enemigos que deben ser destruidos. El hombre y la mujer abiertos al espíritu, también estarán abiertos a un Dios siempre mayor. Esta es la nueva tierra con hombres y mujeres también nuevos. La nueva humanidad espera contra toda esperanza y posee una alegría a toda prueba, en su larga y diffcil tarea por construir un mundo más justo y pacífico. Es una esperanza abierta a lo bueno y al amor e incansable ante las dificultades. Por eso, mueve a la alegría y al don. 
La propuesta de Ellacuría puede parecer un sueño inútil, pero, en realidad, es un esfuerzo por concretar esa nueva manera de entender la paz; pues no se trata sólo de una nueva idea, sino de explorar la manera para llevarla a cabo. Más que un sueño inútil, es una utopía, la utopía del reino de Dios. El paso de las condiciones de vida actuales muy poco humanas a otras más humanas se anuncia lleno de dificultades e incertidumbres, pero es posible comenzar a recorrerlo con la ayuda de la profecía. No es evidente en qué consista la plenitud de la vida y menos cómo pueda lograrse, pero sí es fácil saber en qué no consiste y cómo no se llega a ella. Es aquí donde la profecia es un instrumento indispensable, porque ella señala la ruta por donde hay que transitar para construir la justicia y la paz, y también avisa cuándo se avanza por el camino equivocado o cuándo se ha perdido el rumbo.

Sólo quienes estén poseídos por una gran esperanza podrán participar en esta marcha profética hacia la utopía. Es una esperanza tan recia y profunda que el ánimo no decae, en una marcha que ya se anuncia larga y diffcil. Sólo quienes tienen espíritu encuentran este esfuerzo lleno de sentido y cargado de promesa. Al ser cristiana, es una esperanza contra toda esperanza. Se alimenta de los pequeños logros que va alcanzado en su recorrido. Su cálculo no es materialista, ni su sueño es idealista. La clave de su fuerza radica en la promesa liberadora de Dios, que invita a un éxodo para buscar la tierra prometida. Un éxodo que avanza en medio de las incertidumbres de los logros y los fracasos históricos, pero cuyo ánimo no decae, convencido de la certeza de la promesa. 